\title{
Glaucoma in patients with shunt-treated normal pressure hydrocephalus
}

\author{
Pasquale Gallina, MD, ${ }^{1}$ Alfonso Savastano, MD, ${ }^{2}$ Eleonora Becattini, MD, ${ }^{1}$ Simone Orlandini, MD, ${ }^{1}$ \\ Antonio Scollato, MD, PhD, ${ }^{3}$ Stanislao Rizzo, MD, ${ }^{2}$ Giulia Carreras, PhD, ${ }^{4}$ Nicola Di Lorenzo, MD, ${ }^{1}$ \\ and Berardino Porfirio, MD ${ }^{5}$
}

\begin{abstract}
1'Department of Surgery and Translational Medicine, Neurosurgery Unit, Tuscany School of Neurosurgery, University of Florence; ${ }^{2}$ Department of Surgery and Translational Medicine, Ophthalmic Unit, University of Florence; ${ }^{3}$ Neurosurgery Unit, University Hospital "Ospedali Riuniti" of Trieste, Cattinara; ${ }^{0}$ Occupational \& Environmental Epidemiology Section, Cancer Prevention and Research Institute (ISPO), Florence; and "Department of Clinical and Experimental Biomedical Sciences "Mario Serio," University of Florence, Italy
\end{abstract}

OBJECTIVE Changes in the pressure gradient between intraocular and intracranial compartments at the lamina cribrosa level are a possible explanation of normal tension glaucoma (NTG). Shunt-treated normal pressure hydrocephalus (NPH) is a model for testing whether the increase (time from disease onset to CSF shunt placement, i.e., "protection period") and decrease (time from shunt placement to observation, i.e., "exposure period") in intracranial pressure (ICP) are glaucoma protective or risk factors, respectively. The authors estimated the prevalence of NTG in patients with shunttreated NPH and calculated the extent of optic nerve exposure to changes in the trans-lamina cribrosa gradient.

METHODS Data obtained in patients with NPH who had undergone ventriculoperitoneal (VP) shunt placement were analyzed. Patients with more than 6 months' follow-up, no pathologies associated with ICP changes or CSF dynamics disturbances, and no surgical or valve-related complications were scheduled for ophthalmic evaluation.

RESULTS Nine of 22 patients had NTG, which is about a 40 -fold increase in rate compared with the rate in the general elderly population without hydrocephalus $(p<0.001)$. The median protection period was 12.0 months in patients with NTG and 18.0 months in those without NTG ( $p=0.033)$. The median ICP decrease multiplied by duration of exposure in months was $76.0 \mathrm{~mm} \mathrm{Hg} \times$ months in the NTG group and $24.1 \mathrm{~mm} \mathrm{Hg} \times$ months in the no-NTG group $(p=0.048)$. The patients' median adjusted age (adjusted for "protection" and "exposure" times) was 85.1 years in the NTG group and 78.8 years in the no-NTG group ( $p=0.001)$.

CONCLUSIONS A crucial risk factor for development of NTG in patients with shunt-treated NPH is the duration of optic nerve exposure to the lowering of ICP. Patients with NPH who are candidates for CSF shunting should be informed of the risk of incurring glaucoma. Longitudinal studies could provide estimates of tolerated times for a given ICP decrease. https://thejns.org/doi/abs/10.3171/2017.5.JNS163062

KEY WORDS CSF diversion; intracranial hypotension; normal pressure hydrocephalus; normal tension glaucoma; trans-lamina cribrosa gradient

$\mathrm{G}$ LAUCOMA is a complex, heterogeneous disease characterized by progressive damage of the optic nerve consisting in the loss of retinal ganglion cells, which can lead to irreversible blindness..$^{15}$ Increased intraocular pressure (IOP) is recognized as a leading cause, by means of incompletely clarified mechanisms, of the most prevalent type of glaucoma..$^{15}$ On the other hand, the same visual field defects are also seen in normal tension glauco- ma (NTG), an age-related condition in which the IOP does not exceed the normal range. ${ }^{15}$ The cause of optic nerve damage in NTG remains an enigma. Vasospasm, systemic hypotension, accumulation of toxins, inflammation, and immune etiologies have been advocated as possible mechanisms ${ }^{27,29}$ However, the focus has shifted to changes in IOP and intracranial pressure (ICP) gradients across the lamina cribrosa, which forms the anatomical floor of the optic

ABBREVIATIONS ICP = intracranial pressure; IOP = intraocular pressure; NPH = normal pressure hydrocephalus; NTG = normal tension glaucoma; VP = ventriculoperitoneal.

SUBMITTED December 5, 2016. ACCEPTED May 23, 2017

INCLUDE WHEN CITING Published online November 17, 2017; DOI: 10.3171/2017.5.JNS163062. 
nerve head and separates the 2 pressurized compartments. Simultaneous measurement of the IOP and ICP in healthy adults has shown that the optic nerve is exposed in the supine position to a posteriorly directed IOP - ICP difference $(\Delta \mathrm{P})$ of about $6.7 \mathrm{~mm} \mathrm{Hg}$, whereas in the sitting position, the ICP is lower than in the supine position, resulting in $\Delta$ Ps as high as $15 \mathrm{~mm} \mathrm{Hg.}{ }^{11}$ According to the trans-lamina cribrosa gradient hypothesis, ${ }^{24,30} \Delta \mathrm{P}$ increases, due to either high IOP or low ICP, could be responsible for optic nerve damage, as supported by measurements in patients with hypertensive glaucoma and NTG. ${ }^{2}$ Counterintuitively, both IOP and ICP are elevated in benign ocular hypertension. ${ }^{2}$ Even though more experimental and clinical studies have been advocated to demonstrate the actual role of the trans-lamina cribrosa gradient in NTG pathogenesis, ${ }^{24}$ the correlation between low ICP values and NTG occurrence has been extensively reported. Berdahl et al. ${ }^{2}$ retrospectively demonstrated that patients with NTG had significantly reduced ICP, as measured by lumbar puncture, compared with controls $(8.7 \pm 1.16$ vs $11.8 \pm 0.71 \mathrm{~mm} \mathrm{Hg})$. In a prospective study, Ren et al. ${ }^{21}$ demonstrated that lumbar CSF pressure was significantly lower in patients with NTG (9.5 $\pm 2.2 \mathrm{~mm} \mathrm{Hg}$ ) than in patients with hypertensive glaucoma $(11.7 \pm 2.7 \mathrm{~mm} \mathrm{Hg})$ or controls $(12.9 \pm 1.9 \mathrm{~mm} \mathrm{Hg})$. Moreover, Siaudvytyte et al. ${ }^{25}$ reported that in patients with NTG with differing ICP measurements (as measured by transcranial Doppler ultrasonography), lower ICP was associated with more pronounced structural glaucomatous damage than higher ICP was. However, the temporal dimension of the optic nerve exposure to the barometric insult, which should be considered the other essential component of the theory, has not been sufficiently addressed so far.

Normal pressure hydrocephalus (NPH) refers to a neurological disorder of the elderly in which endoventricular CSF accumulation is associated with Hakim's triad-gait, cognitive, and sphincter disturbances. ${ }^{1}$ Despite the historical designation of this entity, ICP values as measured by intracranial monitoring in the supine position have been reported to be somewhat elevated $(12.1 \pm 4.7 \mathrm{~mm} \mathrm{Hg}){ }^{3}$ Moreover, ICP measured by lumbar puncture in the lateral recumbent position was found to be on average 2.2 $\mathrm{mm} \mathrm{Hg}$ higher than that measured in normal volunteers, although the 2 distributions largely overlapped. ${ }^{20} \mathrm{NPH}$ patients may benefit from CSF diversion,${ }^{14}$ a procedure that has been shown to be associated with an ICP lowering of 3 $\mathrm{mm} \mathrm{Hg}$ on average as measured by lumbar CSF dynamic investigations in a sample of $51 \mathrm{NPH}$ patients with a mean presurgery ICP of $12.5 \pm 2.1 \mathrm{~mm} \mathrm{Hg} .{ }^{19}$

If trans-lamina cribrosa gradient changes have a role in the pathogenesis of NTG, shunt surgery might induce or accelerate glaucomatous damage in NPH patients. ${ }^{4}$ Therefore, shunt-treated NPH may be an appropriate model for testing the hypothesis that ICP hypertension is protective while hypotension is a risk factor for NTG over time. Testing this hypothesis might not only add to the understanding of NTG pathogenesis, but also have a crucial impact on NPH treatment. In this study, we estimated the prevalence of optic nerve damage in patients with NPH who had undergone ventriculoperitoneal (VP) shunt placement and we calculated the extent of the optic nerve exposure to $\Delta \mathrm{P}$ changes in relation to NTG occurrence.

\section{Methods}

This study was conducted according to the principles of the Declaration of Helsinki and was approved by the local ethics committee (Comitato Etico Area Vasta Centro, Regione Toscana). The analysis was carried out in a sequential manner in order to stop enrollment when an NTG prevalence significantly higher than that of the Italian population was reached. Given that the prevalence of NTG in Italians over 70 years of age is $1.1 \%, 5$ the required sample size for having $80 \%$ statistical power to detect a statistically significant $(\alpha=0.05) 3-, 5-$, or 9-fold significant increase was 260,80 , and 25 , respectively. With the aim of selecting patients for the prospective phase of the study, we reviewed from our files the records of all NPH patients who had undergone VP shunt placement according to previously reported protocols. ${ }^{23}$ The exclusion criteria were cognitive status insufficient to grant informed consent (Mini-Mental State Examination ${ }^{12}$ score $\leq 18$ ); less than 6 months' follow-up; pre- or postshunt pathologies associated with ICP changes (e.g., endocranial tumors and hemorrhages with mass effect) or with disturbances of CSF dynamics (e.g., subarachnoid hemorrhage and infections); surgical complications; shunt malfunction; shunt closure; and programmable valve opening pressure adjustment to a value higher than that set at surgery. NPH had been diagnosed on the basis of at least 2 of the triad disturbances associated with the condition as well as the presence of ventriculomegaly (Evans ratio $>0.30$ ). Preoperatively, the patients' cognitive function had been evaluated by the Mini-Mental State Examination test; urinary disorders had been scored according to a urinary incontinence scale graded in 4 categories from normal urinary function to complete incontinence; and gait disorders had been evaluated by means of a gait scale graded into 4 categories ranging from normal gate to inability to walk independently. Patients had been selected for surgery on the basis of definite improvement after prolonged external lumbar drainage. The VP shunt system consisted of a catheter positioned in the frontal horn of the nondominant hemisphere, connected through interposition of a fixedpressure or programmable valve to a second catheter whose distal end was positioned in the suprahepatic space.

In the prospective phase of the study, candidates were randomly scheduled for a single-session visit where written consent was acquired. The patients' age at this visit and at NPH onset, date of surgery, type of valve, opening pressure valve setting (as ICP proxy) at surgery and at any adjustment, and the time interval between adjustments were recorded. Moreover, Hakim's triad ${ }^{1}$ was assessed using the same preshunt criteria. In comparison with preshunt status, a patient was considered improved when he or she gained at least 2 points by the union of the urinary and gait scales or when the patient gained 1 point on either the urinary or the gait scales and at least 3 points on the Mini-Mental State Examination test. Ophthalmic anamnesis was obtained to exclude patients with preshunt glaucoma. Patients with either preexistent or intervening diseases affecting the optic nerve and/or compromising clinical/instrumental inspection (e.g., severe ocular trauma, retinal detachment, uveitis, optic nerve inflammation, advanced cataract, or corneal opacity) were also excluded. 
Enrolled patients received visual acuity and IOP measurement (Goldmann applanation tonometry), biomicroscopy evaluation of the anterior segment, and fundus examination (after dilation with $1 \%$ tropicamide drops). Corneal central thickness was evaluated in both eyes by specular microscopy (CSO Perseus). Optical coherence tomography (DRI OCT Triton plus, Topcon Medical Systems Inc.) of the optic nerve head was performed in each patient's eyes to assess disc retinal nerve fiber layer and optic nerve head morphology. A visual field test (Humphrey Field Analyzer, Zeiss) was done (in a subsequent session) in those patients in whom 1 or more of the following findings were monolaterally or bilaterally found either on physical examination (increased excavation, bayonet vessels, lamina cribrosa exposure, presence of splinter hemorrhages, thinning of the neural rim, or pallor of optic nerve head) or instrumental assessment (disc retinal nerve fiber layer $<75$ $\mu \mathrm{m}$ in at least 1 quadrant associated with an optic nerve head vertical cup disc ratio $>0.50$ at optical coherence tomography). ${ }^{15}$ Monolateral or bilateral findings of focal, generalized, or mixed defects revealed by the visual field test were assessed by evaluating the mean deviation and pattern standard deviation. The cellular ganglion layer and macular retinal nerve fiber layer were evaluated as well. Patients were considered to have NTG if they had an IOP $<21 \mathrm{~mm} \mathrm{Hg}$, corneal central thickness $\geq 520 \mu \mathrm{m}$, and vertical cup disc ratio $>0.50$ in association with mean deviation $<-2 \mathrm{~dB}$ and pattern standard deviation $>2 \mathrm{~dB}$. Optic nerve head pictures and optical coherence tomography data were independently evaluated by an ophthalmologist experienced in glaucoma, who was blind to the aim of the study, to assess concordance of evaluations.

$\mathrm{R}$ version 3.3.1 was used for computing summary statistics, the binomial test, the conditional test, the Fisher exact test for categorical and count data, and the MannWhitney U-test for quantitative data.

\section{Results}

A total of $320 \mathrm{NPH}$ patients underwent VP shunt placement between 2006 and 2016 and met the criteria for enrollment in the prospective phase of the study. From March to September 2016, 25 of these patients were evaluated in Florence. Two of these 25 patients did not undergo ophthalmic appraisal because of noncompliance, and one was excluded from the study because of open-angle glaucoma (both eyes $>28 \mathrm{~mm} \mathrm{Hg}$, average corneal central thickness $530 \mu \mathrm{m})$. Out of the remaining 22 patients, 9 had NTG, resulting in a prevalence of $40.9 \%$ (95\% CI 20.7\%-63.6\%). An exact 1-sided binomial test showed that the sample NTG prevalence in this patient group was significantly higher than that in the general Italian population $(p<0.001)$. Thus, in a sequential analysis we decided to suspend further enrollment for the aims of the present study.

Table 1 shows the demographic and ophthalmic characteristics of the 22 shunt-treated NPH patients stratified by NTG. Details on instrumental glaucoma assessment of the 9 patients with NTG (NTG group) are shown in Table 2. Ophthalmic evaluations by the independent observer were completely concordant. All patients with glaucoma were
TABLE 1. Demographic and ophthalmic characteristics of 9 patients (18 eyes) who developed NTG and of 13 patients (26 eyes) who did not develop NTG after placement of VP shunt to treat NPH

\begin{tabular}{lccc}
\hline \multicolumn{1}{c}{ Characteristic } & $\begin{array}{c}\text { NTG } \\
\text { Group }\end{array}$ & $\begin{array}{c}\text { No-NTG } \\
\text { Group }\end{array}$ & $\begin{array}{c}\text { p } \\
\text { Value* }\end{array}$ \\
\hline Sex, \% male & 55.6 & 53.8 & $0.64 \dagger$ \\
\hline Age in yrs & $78.1(72.8-87.2)$ & $75.3(68.3-86.2)$ & 0.25 \\
\hline $\begin{array}{c}\text { Average IOP in } \\
\text { mm Hg }\end{array}$ & $16.0(12.0-18.5)$ & $16.0(12.0-20.0)$ & 0.36 \\
\hline $\begin{array}{l}\text { Average CCT } \\
\text { in } \mu \mathrm{m}\end{array}$ & $545(520-586)$ & $535(521-619)$ & 0.06 \\
\hline $\begin{array}{l}\text { Average disc } \\
\text { RNFL in } \mu \mathrm{m}\end{array}$ & $97(82-100)$ & $93(83-110)$ & 0.30 \\
\hline $\begin{array}{l}\text { Average rim area } \\
\text { in mm }\end{array}$ & $1.05(0.83-1.48)$ & $2.26(1.68-2.96)$ & $<0.001$ \\
\hline $\begin{array}{l}\text { Average hCDR } \\
\text { Average vCDR }\end{array}$ & $0.69(0.58-0.83)$ & $0.50(0.30-0.69)$ & $<0.001$ \\
\hline $\begin{array}{l}\text { Average cup disc } \\
\text { area ratio }\end{array}$ & $0.57(0.57-0.77)$ & $0.54(0.24-0.62)$ & $<0.001$ \\
\hline
\end{tabular}

$\mathrm{CCT}$ = corneal central thickness; $\mathrm{hCDR}=$ horizontal cup disc ratio; RNFL = retinal nerve fiber layer; $v C D R=$ vertical cup disc ratio.

Data are presented as median (range) unless otherwise indicated. For ophthalmic data, averaged figures of both eyes were used.

* Based on Mann-Whitney U-test unless otherwise indicated.

$\dagger$ Fisher exact test.

referred to our Glaucoma Center for therapy and followup. Combined ophthalmic-neurosurgical evaluation was scheduled for patients in the no-NTG group.

Tables 3 and 4 display data on the neurosurgical assessment of patients in the NTG and no-NTG groups, respectively. In the NTG group the median age of NPH onset was 71.6 years (range $65.5-77.4$ years); the median age at shunt placement was 72.5 years (range 66.0-78.3 years); the median age at the single study visit was 78.1 years (range 72.8-87.2 years). VP shunt placement involved implantation of a medium-pressure $(8.1 \mathrm{~mm} \mathrm{Hg})$ fixed valve in 3 cases and an adjustable valve in 6 cases (set at 8.1 $\mathrm{mm} \mathrm{Hg}$ in 5 cases and at $6.6 \mathrm{~mm} \mathrm{Hg}$ in 1 case). The initial valve setting remained unchanged in 5 of the 9 patients in this group, while the others underwent 1 or more downward adjustments. The median opening pressure valve at visit was $6.6 \mathrm{~mm} \mathrm{Hg}$ (range $3.7-8.1 \mathrm{~mm} \mathrm{Hg}$ ). Compared with their neurological status at shunt placement, 6 patients were improved at the visit, while 3 were not. In the no-NTG group the estimated median age of NPH onset was 69.6 years (range 61.8-82.5 years); the median age at shunt placement was 73.7 years (range 62.8-84.5 years); the median age at visit was 75.3 years (range 68.3-86.2 years). Shunt placement involved implantation of a medium-pressure $(8.1 \mathrm{~mm} \mathrm{Hg})$ fixed valve in 4 cases and an adjustable valve in 9 cases (set at $8.1 \mathrm{~mm} \mathrm{Hg}$ in 8 cases and at $8.8 \mathrm{~mm} \mathrm{Hg}$ in 1 case). The initial valve setting remained unchanged in 10 of the 13 patients in this group, while the other 3 patients had 1 or more downward adjustments. The median opening pressure valve at visit was $8.1 \mathrm{~mm} \mathrm{Hg}$ (range 5.2-8.8 $\mathrm{mm} \mathrm{Hg}$ ). Compared with their neurologi- 
TABLE 2. Instrumental glaucoma assessment of 9 patients with NPH who developed NTG after VP shunt placement

\begin{tabular}{|c|c|c|c|c|c|c|c|c|}
\hline \multirow[b]{2}{*}{ Case No. } & \multicolumn{2}{|c|}{ Macular RNFL $(\mu \mathrm{m})$} & \multicolumn{2}{|c|}{$\mathrm{GCL}(\mu \mathrm{m})$} & \multicolumn{2}{|c|}{$\mathrm{MD}(\mathrm{dB})$} & \multicolumn{2}{|c|}{ PSD (dB) } \\
\hline & RE & LE & RE & LE & RE & LE & RE & LE \\
\hline 1 & 36 & 37 & 56 & 57 & -15.9 & -12.1 & +10.8 & +8.4 \\
\hline 2 & 39 & 36 & 63 & 62 & -8.1 & -8.5 & +6.9 & +7.7 \\
\hline 3 & 33 & 29 & 59 & 57 & -3.2 & -4.9 & +2.5 & +2.1 \\
\hline 7 & 27 & 28 & 58 & 55 & -2.9 & -3.7 & +3.2 & +1.9 \\
\hline 8 & 42 & 37 & 54 & 52 & -5.1 & -5.9 & +3.2 & +4.5 \\
\hline 15 & 35 & 34 & 60 & 58 & -4.2 & -4.5 & +2.5 & +2.0 \\
\hline 19 & 37 & 32 & 58 & 60 & -12.7 & -5.6 & +7.5 & +5.4 \\
\hline 21 & 35 & 32 & 60 & 61 & -4.1 & -3.9 & +5.4 & +4.6 \\
\hline 22 & 14 & 25 & 42 & 48 & -26.6 & -26.1 & +5.4 & +5.9 \\
\hline Normative values & \multicolumn{2}{|c|}{$\geq 35$} & \multicolumn{2}{|c|}{$\geq 55$} & \multicolumn{2}{|c|}{$\geq-2$} & \multicolumn{2}{|c|}{$\leq+2$} \\
\hline
\end{tabular}

$\mathrm{GCL}$ = ganglion cell layer; $\mathrm{LE}=$ left eye; $\mathrm{MD}=$ mean deviation; $\mathrm{PSD}=$ pattern standard deviation; $\mathrm{RE}$ = right eye.

The macular retinal nerve fiber layer and ganglion cell layer were measured by DRI OCT Triton plus, Topcon Medical Systems Inc.; mean deviation and pattern standard deviation were assessed by Humphrey Field Analyzer, Zeiss. Normative values are from the manufacturers. Abnormal values are in boldface type.

cal status at shunt placement, 9 patients were improved at the visit, while 4 were not. Marginal or not significant differences in NPH-related characteristics emerged between the NTG and no-NTG groups. In particular, homogeneity tests showed: age at NPH onset $(\mathrm{p}=0.28)$; age at shunt $(\mathrm{p}$ $=0.39)$; age at visit $(\mathrm{p}=0.25)$; valve type $(\mathrm{p}=0.63)$; initial valve setting $(\mathrm{p}=0.46)$; number of valve adjustments ( $\mathrm{p}$ $=0.32)$; valve setting at visit $(\mathrm{p}=0.06)$; and clinical improvement $(\mathrm{p}=0.63)$.

The median $\Delta \mathrm{P}$, i.e., the difference between IOP and ICP (valve opening pressure value at visit), was $8.3 \mathrm{~mm}$ $\mathrm{Hg}$ (range 3.9-13.4 $\mathrm{mm} \mathrm{Hg}$ ) in the NTG group and $7.9 \mathrm{~mm}$ $\mathrm{Hg}$ (range 3.9-13.4 mm Hg) in the no-NTG group ( $\mathrm{p}=$ $0.274)$. The median duration of the "protection period," i.e., the time span between NPH onset and shunt dates, was 12 months (range 3-36 months) in the NTG group and 18 months (range 12-96 months) in the no-NTG group ( $\mathrm{p}=$ 0.033). The median duration of the "exposure period," i.e., the time span between the shunt placement and visit dates, was 76 months (range 13-122 months) in the NTG group and 20 months (range 6-102 months) in the no-NTG group $(\mathrm{p}=0.102)$. The median $\triangle \mathrm{ICP}$ - the difference between an arbitrarily chosen (see Discussion) preshunt ICP value of $9.1 \mathrm{~mm} \mathrm{Hg}$ and the opening pressure setting at visit-was
$1.0 \mathrm{~mm} \mathrm{Hg}$ (range 1.0-5.4 $\mathrm{mm} \mathrm{Hg}$ ) in the NTG group and $1.0 \mathrm{~mm} \mathrm{Hg}$ (range 1-3.9 mm Hg) in the no-NTG group ( $\mathrm{p}$ $=0.159)$. The median value of $\Delta \mathrm{ICP} \times$ duration of exposure in months was $76.0 \mathrm{~mm} \mathrm{Hg} \times$ months (range 17.8-362.4) and $24.1 \mathrm{~mm} \mathrm{Hg} \times$ months (range 5.9-102.0) in the NTG and no-NTG groups, respectively $(\mathrm{p}=0.048)$. For cases in which 1 or more adjustments took place, $\triangle \mathrm{ICP}$ and duration of exposure were split into defined intervals and their products were summed. The median adjusted age (age at visit $+[($ exposure time/protection time $)-1])$ was 85.1 years (range 73.4-94.1 years) in the NTG group and 78.8 years (range 67.9-86.0 years) in the no-NTG group $(\mathrm{p}=0.001)$.

\section{Discussion}

We demonstrate here that patients whose ICP has been lowered as treatment for NPH are almost 40 times more likely to suffer from NTG than elderly Italian patients without hydrocephalus. ${ }^{5}$ Common issues of pathogenesis are emerging between NTG and NPH, both age-related entities. A neural susceptibility to IOP-related dysfunction on a genetic basis has been advocated in NTG pathogenesis. ${ }^{6}$ Similarly, a genetic susceptibility to ICP-related damage in neural tissue has been described in familial

TABLE 3. Neurosurgical assessment of 9 patients with NPH who developed NTG after VP shunt placement

\begin{tabular}{rccclcccc}
\hline $\begin{array}{c}\text { Case } \\
\text { No. }\end{array}$ & $\begin{array}{c}\text { Age at NPH } \\
\text { Onset (yrs) }\end{array}$ & $\begin{array}{c}\text { Age at VP } \\
\text { Shunt (yrs) }\end{array}$ & $\begin{array}{c}\text { Age at } \\
\text { Visit (yrs) }\end{array}$ & $\begin{array}{c}\text { Valve } \\
\text { Type }\end{array}$ & $\begin{array}{c}\text { Valve Setting } \\
\text { at Op (mm Hg) }\end{array}$ & $\begin{array}{c}\text { No. of Valve } \\
\text { Adjustments }\end{array}$ & $\begin{array}{c}\text { Valve Setting at } \\
\text { Visit (mm Hg) }\end{array}$ & $\begin{array}{c}\text { Hakim's } \\
\text { Triad at Visit }\end{array}$ \\
\hline 1 & 66.9 & 67.5 & 77.7 & Fixed & 8.1 & 0 & 8.1 & Not improved \\
\hline 2 & 74.5 & 77.5 & 87.2 & Adjustable & 8.1 & 5 & 3.7 & Improved \\
\hline 3 & 75.8 & 77.3 & 83.8 & Adjustable & 8.1 & 1 & 6.6 & Not improved \\
\hline 7 & 77.3 & 78.3 & 79.5 & Adjustable & 8.1 & 2 & 5.2 & Improved \\
\hline 8 & 77.4 & 77.7 & 80.2 & Fixed & 8.1 & 0 & 8.1 & Improved \\
\hline 15 & 65.5 & 66.0 & 72.8 & Fixed & 8.1 & 0 & 1 & Improved \\
\hline 19 & 70.5 & 72.5 & 73.8 & Adjustable & 8.1 & 1 & 5.2 & Improved \\
\hline 21 & 71.6 & 72.1 & 75.0 & Adjustable & 6.6 & 0 & 6.6 & Not improved \\
\hline 22 & 70.8 & 71.8 & 78.1 & Adjustable & 8.1 & 0 & 8.1 & Improved \\
\hline
\end{tabular}


TABLE 4. Neurosurgical assessment of 13 patients with NPH undergoing VP shunt treatment who did not show glaucomatous damage

\begin{tabular}{rccclcccc}
\hline $\begin{array}{c}\text { Case } \\
\text { No. }\end{array}$ & $\begin{array}{c}\text { Age at NPH } \\
\text { Onset (yrs) }\end{array}$ & $\begin{array}{c}\text { Age at VP } \\
\text { Shunt (yrs) }\end{array}$ & $\begin{array}{c}\text { Age at } \\
\text { Visit (yrs) }\end{array}$ & $\begin{array}{c}\text { Valve } \\
\text { Type }\end{array}$ & $\begin{array}{c}\text { Valve Setting at } \\
\text { Op (mm Hg) }\end{array}$ & $\begin{array}{c}\text { No. of Valve } \\
\text { Adjustments }\end{array}$ & $\begin{array}{c}\text { Valve Setting at } \\
\text { Visit (mm Hg) }\end{array}$ & $\begin{array}{c}\text { Hakim's Triad } \\
\text { at Visit }\end{array}$ \\
\hline 4 & 72.7 & 73.7 & 75.3 & Adjustable & 8.1 & 1 & 6.6 & Improved \\
\hline 5 & 69.6 & 71.6 & 78.2 & Adjustable & 8.1 & 0 & 8.1 & Not improved \\
\hline 6 & 64.1 & 65.6 & 74.1 & Adjustable & 8.8 & 0 & 8.8 & Improved \\
\hline 9 & 64.0 & 66.5 & 68.3 & Fixed & 8.1 & 0 & 8.1 & Not improved \\
\hline 10 & 73.0 & 77.0 & 77.5 & Adjustable & 8.1 & 0 & 8.1 & Improved \\
\hline 11 & 66.9 & 67.9 & 68.4 & Adjustable & 8.1 & 0 & 8.1 & Improved \\
\hline 12 & 68.9 & 76.9 & 82.0 & Fixed & 8.1 & 0 & 8.1 & Not improved \\
\hline 13 & 72.8 & 73.8 & 75.3 & Adjustable & 8.1 & 0 & 8.1 & Improved \\
\hline 14 & 61.8 & 62.8 & 69.3 & Fixed & 8.1 & 0 & 8.1 & Improved \\
\hline 16 & 69.3 & 70.3 & 75.2 & Fixed & 8.1 & 1 & Not improved \\
\hline 17 & 77.6 & 79.1 & 79.6 & Adjustable & 8.1 & 0 & 8.6 & Improved \\
\hline 18 & 82.5 & 84.5 & 86.2 & Adjustable & 8.1 & 5 & Improved \\
\hline 20 & 78.1 & 80.1 & 84.2 & Adjustable & 8.1 & 5.2 & Improved \\
\hline
\end{tabular}

NPH. ${ }^{28}$ Chang and Singh ${ }^{7}$ retrospectively found high comorbidity between these 2 entities (13 cases of glaucoma in 72 white NPH patients). Due to the lack of distinction between shunt-treated and non-shunt-treated patients, it is impossible to discern how many cases of glaucoma were associated with CSF diversion in that case series. We focused only on shunt-treated patients and excluded those with any preshunt conditions of ophthalmic interest. The risk of NTG in shunt-treated NPH patients is only beginning to emerge, ${ }^{4}$ and guidelines for the diagnosis and management of NPH do not recommend IOP measurement before CSF shunting. ${ }^{17}$ With this in mind, we believe that our study indicates that the occurrence of NTG may in fact be related to the lowering of ICP, thus supporting the hypothesis that an imbalance between IOP and ICP in favor of the intraocular compartment is critical in the development of optic nerve damage.

Precise $\Delta \mathrm{P}$ values are difficult to estimate. While IOP measurement is straightforward, obtaining reliable ICP values requires placement of an intracranial sensor, which is an invasive and risky procedure ${ }^{33}$ Lumbar puncture, besides its inherent invasiveness, yields ICP values that may differ substantially from the ICP around the optic nerve. ${ }^{16}$ Several noninvasive ICP measurement approaches, including ophthalmodynamometry, assessment of tympanic membrane displacement, and measurement of optic nerve sheath diameter, as well as mathematical formulas are considered fairly inaccurate, ${ }^{26}$ although a promising transcranial Doppler ultrasonography method is being explored. ${ }^{25}$ In our study, therapeutic insertion of an endoventricular catheter connected to a pressure valve did not provide an exact ICP value either, although it gave us the maximum reachable ICP. In a model where only downward ICP adjustments are considered, this approximation did not affect our discussion and allowed us to analyze whether and how $\Delta \mathrm{P}$ changes related to CSF diversion operate in determining glaucomatous damage. It should be noted that patients who experienced any pathological condition possibly inducing changes in ICP, as well as those patients who underwent upward valve adjustments, were excluded from the study. This allowed us to attribute the occurrence or the nonoccurrence of optic nerve damage only to the shuntrelated lowering of ICP. We determined that this damage was also seen as an increase in the cup disc area ratio and a reduction in the disc rim area. Our results are in line with those of Siaudvytyte et al., ${ }^{25}$ who found that the neuroretinal rim area is directly proportional to ICP in patients with NTG. Incidentally, the finding that NTG occurs in patients whose CSF clearance was forced more strongly by the sink action of the diversion does not support, as already noted, ${ }^{22}$ a pressure-independent pathogenetic hypothesis, which focuses on the accumulation of toxins at the level of the optic nerve due to failure of CSF dynamics. ${ }^{31}$

More importantly, we demonstrate that a crucial risk factor is the duration of optic nerve exposure to the ICP lowering. The amount of time between shunt placement and observation, i.e., the exposure period, was 76 months in the NTG group versus 20 months in the no-NTG group. Moreover, the median exposure to definite ICP decreases was $76.0 \mathrm{~mm} \mathrm{Hg} \times$ months in the NTG group versus 24.1 $\mathrm{mm} \mathrm{Hg} \times$ months in the no-NTG group $(\mathrm{p}<0.05)$. While ICP lowering after surgery straightforwardly corresponds to opening pressure valve variations, the initial ICP decrease is not calculable since the preshunt ICP value is not known. However, our assumption of a preshunt ICP of $9.1 \mathrm{~mm} \mathrm{Hg}$ led us to compute a postshunt ICP lowering of at least $1 \mathrm{~mm} \mathrm{Hg}$. In a model where we are testing intracranial hypotension as an NTG risk factor, our approach has to be considered quite conservative, since this ICP decrease is less than that reported in the literature. . $^{3,9,10,}$ ${ }^{19,20}$ Moreover, from our data it appears that the relationship between ICP and time also works protectively, where the interval between NPH onset and shunt placement represents a phase of relatively higher ICP. We showed that the median duration of the "protective" phase was significantly longer $(\mathrm{p}<0.05)$ in the no-NTG group than in the NTG group (18 vs 12 months, respectively). It should be noted that these data are biased by the uncertainty regarding the time of onset of NPH, which depends upon patient report. On the whole, our results highlight time as a key 
element in determining optic nerve damage and should encourage further studies to search for a $\Delta \mathrm{P} \times$ time threshold value. Intriguingly, Yusuf et al..$^{32}$ reported on a 27 -year-old patient who experienced NTG ascribed to chronically low ICP following CSF diversion at 2 years of age for the treatment of secondary hydrocephalus.

Age remains the major risk factor for $\mathrm{NTG},{ }^{15}$ and interestingly, the results of our study show that median age, when corrected by protection and exposure periods, was 85.1 in the NTG group versus 78.8 years in the no-NTG group ( $p<0.001)$. In this context, the case reported by Chen et al., ${ }^{8}$ who described the occurrence and disappearance of optic disc hemorrhages following down- and upregulation, respectively, of valve opening pressure in a 93-year-old shunt-treated NPH patient with a history of well-controlled NTG, may be instructive. The observation of this nonagenarian suggests that her diseased optic nerve, which had remained relatively "protected" by a higher ICP for a long time, proved to be sensitive to sudden although small $\Delta \mathrm{P}$ changes. In a context of advanced age, a "fragile" optic nerve may be vulnerable to only modest amounts of $\Delta \mathrm{P}$ changes. Hence, any search for a $\Delta \mathrm{P} \times$ time threshold value should take the subject's age into account.

Even though our results need to be confirmed by longitudinal studies, this paper provides many clinical implications for the management of NPH and argues for close cooperation between the neurosurgeon and ophthalmologist. A preliminary ophthalmic evaluation of an NPH patient should assess possible concomitance with glaucoma. IOP values also need to be measured. If IOP is in the normal range and signs of optic nerve damage are not detected, a candidate for CSF diversion procedures should be informed of a real, although still unquantifiable, risk of incurring glaucomatous damage. Preshunt ICP values should also be useful. In addition to measurement by means of an intracranial sensor, ICP may be estimated during the execution of other tests predictive of responsiveness to CSF diversion, which involve a lumbar puncture, such as a "tap test," external drainage, and infusion test. ${ }^{18}$ Identification of baseline $\Delta \mathrm{P}$ values could drive the fine tuning of valve adjustments for optimal NPH control while minimizing the risk of NTG. We anticipate that NPH patients with higher preshunt ICP are more likely to benefit from modest downward adjustments without incurring glaucomatous damage. These same patients have more room for improvement of possible postoperative optic nerve damage through careful upward adjustments below the threshold of recurrence of NPH signs. Lifetime evaluations of optic nerve status should be scheduled for shunt-treated patients. Since the time span when optic nerve damage may ensue after the shunt is unknown, it is not possible to define the timing of the ophthalmic follow-up to intercept visual impairment as early as possible. Considering that the shortest interval between shunt placement and NTG detection was 13 months in our limited experience, it is reasonable to check the optic nerve within a year of the previous evaluation. IOP values should be known before any downward valve adjustment is made in an effort to improve NPH. Since this procedure implies a $\Delta \mathrm{P}$ increase, patients with higher IOP should be more closely checked because of their higher NTG risk. If NTG was detected preoperative- ly, NPH patients undergoing CSF diversion procedures, even those aimed at assessing shunt responsiveness, should be warned that their glaucoma can significantly and suddenly worsen, particularly in the presence of a relatively low ICP. In principle, these considerations also would hold true when high-pressure glaucoma is encountered.

Another issue raised by our study concerns the management of NPH patients who have been treated with CSF shunting in the past. Since a high NTG rate is expected, we believe that all such patients should receive neuro-ophthalmic follow-up as described above.

When treating a patient with glaucomatous damage associated with normal IOP, the ophthalmologist could take advantage of ICP value knowledge to modulate IOP lowering by medical or even surgical treatments. ICP values could be easily available when noninvasive ICP measurements are definitively validated. Moreover, possible comorbidities resulting in decreased ICP should be investigated in patients with glaucomatous damage, particularly if they are young. Conversely, possible optic nerve damage should be suspected by the neurosurgeon in patients with conditions responsible for a decrease in ICP, such as a CSF leakage.

\section{Conclusions}

Our study indicates that the "ideal" NPH candidate for CSF diversion is the patient with a relatively high ICP in the presence of a relatively low IOP since he or she may benefit from ICP lowering with a relatively low risk of NTG. On the contrary, a "critical" candidate is one whose large $\Delta \mathrm{P}$ limits the likelihood of effective ICP lowering without incurring optic nerve damage. It should be further emphasized that it is safe to set the valve at surgery at as high a pressure value as possible. Since the optic nerve is exposed daily to much higher $\Delta \mathrm{P}$ when the patient is awake than during sleep (thereby producing large $\Delta \mathrm{P}$ excursions), ${ }^{11}$ the use of antigravitational valves, in which the opening pressure varies based on body position, ${ }^{13}$ could limit this kind of insult by decreasing the hydromechanical effect of siphoning.

If NTG represents a clue for conditions associated with ICP hypotension and ICP hypotension warns about optic nerve status, further investigations will be important not only to confirm the validity of the trans-lamina cribrosa gradient hypothesis in a wider spectrum of diseases, but also to allow for intervention where possible.

\section{Acknowledgments}

We wish to thank Dr. Ilaria Biagini for her skillful technical assistance.

\section{References}

1. Adams RD, Fisher CM, Hakim S, Ojemann RG, Sweet WH: Symptomatic occult hydrocephalus with "normal" cerebrospinal-fluid pressure. A treatable syndrome. N Engl J Med 273:117-126, 1965

2. Berdahl JP, Fautsch MP, Stinnett SS, Allingham RR: Intracranial pressure in primary open angle glaucoma, normal tension glaucoma, and ocular hypertension: a case-control study. Invest Ophthalmol Vis Sci 49:5412-5418, 2008

3. Bergsneider M, Yang I, Hu X, McArthur DL, Cook SW, Boscardin WJ: Relationship between valve opening pressure, body position, and intracranial pressure in normal pressure 
hydrocephalus: paradigm for selection of programmable valve pressure setting. Neurosurgery 55:851-859, 2004

4. Bokhari RF, Baeesa SS: Does the treatment of normal pressure hydrocephalus put the retinal ganglion cells at risk? A brief literature review and novel hypothesis. Med Hypotheses 81:686-689, 2013

5. Bonomi L, Marchini G, Marraffa M, Bernardi P, De Franco I, Perfetti S, et al: Prevalence of glaucoma and intraocular pressure distribution in a defined population. The Egna-Neumarkt Study. Ophthalmology 105:209-215, 1998

6. Chang TC, Congdon NG, Wojciechowski R, Muñoz B, Gilbert D, Chen P, et al: Determinants and heritability of intraocular pressure and cup-to-disc ratio in a defined older population. Ophthalmology 112:1186-1191, 2005

7. Chang TC, Singh K: Glaucomatous disease in patients with normal pressure hydrocephalus. J Glaucoma 18:243-246, 2009

8. Chen BH, Drucker MD, Louis KM, Richards DW: Progression of normal-tension glaucoma after ventriculoperitoneal shunt to decrease cerebrospinal fluid pressure. J Glaucoma 25:e50-e52, 2016

9. Eide PK, Brean A: Cerebrospinal fluid pulse pressure amplitude during lumbar infusion in idiopathic normal pressure hydrocephalus can predict response to shunting. Cerebrospinal Fluid Res 7:5, 2010

10. Eide PK, Sorteberg W: Outcome of surgery for idiopathic normal pressure hydrocephalus: role of preoperative static and pulsatile intracranial pressure. World Neurosurg 86:186-193.e1, 2016

11. Eklund A, Jóhannesson G, Johansson E, Holmlund P, Qvarlander S, Ambarki K, et al: The pressure difference between eye and brain changes with posture. Ann Neurol 80:269276, 2016

12. Folstein MF, Folstein SE, McHugh PR: "Mini-mental state". A practical method for grading the cognitive state of patients for the clinician. J Psychiatr Res 12:189-198, 1975

13. Gölz L, Lemcke J, Meier U: Indications for valve-pressure adjustments of gravitational assisted valves in patients with idiopathic normal pressure hydrocephalus. Surg Neurol Int 4:140, 2013

14. Halperin JJ, Kurlan R, Schwalb JM, Cusimano MD, Gronseth G, Gloss D: Practice guideline: Idiopathic normal pressure hydrocephalus: Response to shunting and predictors of response: Report of the Guideline Development, Dissemination, and Implementation Subcommittee of the American Academy of Neurology. Neurology 85:2063-2071, 2015

15. Kanski JJ, Bowling B: Clinical Ophthalmology. A Systematic Approach. London: Elsevier, 2011

16. Killer HE: Compartment syndromes of the optic nerve and open-angle glaucoma. J Glaucoma 22 (Suppl 5):S19-S20, 2013

17. Marmarou A, Bergsneider M, Black PM, Klinge P, Relkin N: Guidelines for the diagnosis and management of idiopathic normal-pressure hydrocephalus. Neurosurgery 57 (Suppl 3):S2-1-S2-52, 2005

18. Marmarou A, Bergsneider M, Klinge P, Relkin N, Black PM: The value of supplemental prognostic tests for the preoperative assessment of idiopathic normal-pressure hydrocephalus. Neurosurgery 57 (Suppl 3):S2-17-S2-28, 2005

19. Qvarlander S, Lundkvist B, Koskinen LO, Malm J, Eklund A: Pulsatility in CSF dynamics: pathophysiology of idiopathic normal pressure hydrocephalus. J Neurol Neurosurg Psychiatry 84:735-741, 2013

20. Relkin N, Marmarou A, Klinge P, Bergsneider M, Black PM: Diagnosing idiopathic normal-pressure hydrocephalus. Neurosurgery (Suppl 3) 57:S2-4-S2-16, 2005

21. Ren R, Jonas JB, Tian G, Zhen Y, Ma K, Li S, et al: Cerebrospinal fluid pressure in glaucoma: a prospective study. Ophthalmology 117:259-266, 2010

22. Savastano A, Porfirio B, Rizzo S, Gallina P: Re: Fast circulation of cerebrospinal fluid: an alternative perspective on the protective role of high intracranial pressure in ocular hypertension. Clin Exp Optom 99:607, 2016 (Letter)

23. Scollato A, Gallina P, Gautam B, Pellicanò G, Cavallini C, Tenenbaum R, et al: Changes in aqueductal CSF stroke volume in shunted patients with idiopathic normal-pressure hydrocephalus. AJNR Am J Neuroradiol 30:1580-1586, 2009

24. Siaudvytyte L, Januleviciene I, Daveckaite A, Ragauskas A, Bartusis L, Kucinoviene J, et al: Literature review and metaanalysis of translaminar pressure difference in open-angle glaucoma. Eye (Lond) 29:1242-1250, 2015

25. Siaudvytyte L, Januleviciene I, Daveckaite A, Ragauskas A, Siesky B, Harris A: Neuroretinal rim area and ocular haemodynamic parameters in patients with normal-tension glaucoma with differing intracranial pressures. Br J Ophthalmol 100:1134-1138, 2016

26. Siaudvytyte L, Januleviciene I, Ragauskas A, Bartusis L, Siesky B, Harris A: Update in intracranial pressure evaluation methods and translaminar pressure gradient role in glaucoma. Acta Ophthalmol 93:9-15, 2015

27. Soldatos T, Chatzimichail K, Papathanasiou M, Gouliamos A: Optic nerve sonography: a new window for the noninvasive evaluation of intracranial pressure in brain injury. Emerg Med J 26:630-634, 2009

28. Takahashi Y, Kawanami T, Nagasawa H, Iseki C, Hanyu H, Kato T: Familial normal pressure hydrocephalus (NPH) with an autosomal-dominant inheritance: a novel subgroup of NPH. J Neurol Sci 308:149-151, 2011

29. Tayal VS, Neulander M, Norton HJ, Foster T, Saunders T, Blaivas M: Emergency department sonographic measurement of optic nerve sheath diameter to detect findings of increased intracranial pressure in adult head injury patients. Ann Emerg Med 49:508-514, 2007

30. Volkov VV: [Essential element of the glaucomatous process neglected in clinical practice.] Oftalmol Zh 31:500-504, 1976 (Russian)

31. Wostyn P, De Groot V, Van Dam D, Audenaert K, De Deyn PP: Senescent changes in cerebrospinal fluid circulatory physiology and their role in the pathogenesis of normaltension glaucoma. Am J Ophthalmol 156:5-14.e2, 2013

32. Yusuf IH, Ratnarajan G, Kerr RS, Salmon JF: Juvenile-onset normal tension glaucoma from chronic, recurrent low cerebrospinal fluid pressure. J Glaucoma 25:e738-e740, 2016

33. Zeng T, Gao L: Management of patients with severe traumatic brain injury guided by intraventricular intracranial pressure monitoring: a report of 136 cases. Chin J Traumatol 13:146-151, 2010

\section{Disclosures}

The authors report no conflict of interest concerning the materials or methods used in this study or the findings specified in this paper.

\section{Author Contributions}

Conception and design: Porfirio, Gallina, Scollato, Rizzo, Di Lorenzo. Acquisition of data: Savastano, Becattini, Orlandini, Scollato. Analysis and interpretation of data: Porfirio, Gallina, Savastano, Becattini, Orlandini. Drafting the article: Porfirio, Gallina, Savastano, Becattini, Orlandini. Critically revising the article: Scollato, Rizzo, Carreras, Di Lorenzo. Reviewed submitted version of manuscript: Carreras. Approved the final version of the manuscript on behalf of all authors: Porfirio. Statistical analysis: Porfirio, Carreras. Study supervision: Rizzo, Di Lorenzo.

\section{Correspondence}

Berardino Porfirio, Department of Clinical and Experimental Biomedical Sciences “Mario Serio," Viale Gaetano Pieraccini, 6, Florence I-50139, Italy. email: nporfirio@unifi.it. 